\title{
Symptomatic presentation of cervical cancer in emergency departments in California
}

\author{
Frances B. Maguire ${ }^{1,4}$ (D) Julianne J. P. Cooley ${ }^{1}$ Cyllene R. Morris ${ }^{1} \cdot$ Arti Parikh-Patel $^{1} \cdot$ Vanessa A. Kennedy $^{2}$. \\ Theresa H. M. Keegan ${ }^{1,3}$
}

Received: 24 April 2021 / Accepted: 13 August 2021 / Published online: 23 August 2021

(C) The Author(s) 2021

\begin{abstract}
Purpose Through screening and HPV vaccination, cervical cancer can mostly be prevented or detected very early, before symptoms develop. However, cervical cancer persists, and many women are diagnosed at advanced stages. Little is known about the degree to which U.S. women may begin their diagnostic workup for cervical cancer in Emergency Departments (ED). We sought to quantify the proportion of women presenting symptomatically in the ED prior to their diagnosis with cervical cancer and to describe their characteristics and outcomes.

Methods We identified women diagnosed from 2006 to 2017 with cervical cancer in the California Cancer Registry. We linked this cohort to statewide ED discharge records to determine ED use and symptoms present at the encounter. Multivariable logistic regression models examined associations with ED use and multivariable Cox proportional hazards regression models examined associations with survival.

Results Of the more than 16,000 women with cervical cancer in the study cohort, $28 \%$ presented symptomatically in the ED prior to diagnosis. Those presenting symptomatically were more likely to have public (odds ratio [OR] 1.16; 95\% confidence interval [CI] 1.06-1.27) or no insurance (OR 4.81; CI 4.06-5.71) (vs. private), low socioeconomic status (SES) (OR 1.76; CI 1.52-2.04), late-stage disease (OR 5.29; CI 4.70-5.96), and had a 37\% increased risk of death (CI 1.28-1.46).

Conclusion Nearly a third of women with cervical cancer presented symptomatically, outside of a primary care setting, suggesting that many women, especially those with low SES, may not be benefiting from screening or healthcare following abnormal results.
\end{abstract}

Keywords Cervical cancer $\cdot$ Emergency department $\cdot$ Symptomatic presentation $\cdot$ Socioeconomic status $\cdot$ Population-based

Frances B. Maguire

fbmaguire@ucdavis.edu

1 California Cancer Reporting and Epidemiologic Surveillance Program, University of California Davis Comprehensive Cancer Center, Sacramento, CA, USA

2 Department of Gynecology Oncology, University of California Davis Comprehensive Cancer Center, Sacramento, CA, USA

3 Center for Oncology Hematology Outcomes Research and Training (COHORT) and Division of Hematology and Oncology, University of California Davis School of Medicine, Sacramento, CA, USA

4 California Cancer Reporting and Epidemiologic Surveillance Program, University of California Davis Comprehensive Cancer Center, 1631 Alhambra Blvd., Suite 200, Sacramento, CA 95816, USA

\section{Introduction}

Cervical cancer has both effective screening strategies (Pap and human papillomavirus [HPV] testing) [1] and since 2006 vaccines against HPV, the causative agent in the vast majority of cases [2]. After large declines in incidence and mortality, rates have plateaued since 2012 [3] with approximately 13,000 diagnoses and 4,200 deaths each year in the United States (U.S.) [4]. Many women still are diagnosed at advanced stages when survival is poor [4] despite the ability of screening to detect precancer and early-stage cancer of the cervix [1].

Not all women are benefiting from cervical cancer prevention tools. Cervical cancer screening declined from 2000 to 2015 and is below the Healthy People 2020 target [5]. HPV vaccination rates among girls by age $15(46 \%)$ remain far behind target levels of $80 \%$ [6]. Having a primary care 
provider has been identified as a key strategy in cervical cancer prevention [7]. Safety-net healthcare systems face a large burden of cervical cancer patients with no prior healthcare contact, and many began their diagnostic process in the emergency department (ED), presenting with symptoms [7]. Patients with symptoms at diagnosis often have more advanced disease [8]. Nationally representative studies on cervical cancer presentation in the emergency department are lacking. Prior work has focused on ED care for patients with gynecologic cancers after their diagnosis or ED diagnostic workup among all cancer patients [9-12].

Therefore, we sought to quantify the number of women presenting symptomatically to the ED in the months prior to their cervical cancer diagnosis and describe their characteristics and survival outcomes in a large population-based cohort. Describing this population of women presenting outside of a primary care setting can highlight patient factors associated with barriers to preventive healthcare, and in turn identify opportunities for intervention.

\section{Methods}

\section{Study population}

We identified women diagnosed with a first primary cervical cancer from 2006 to 2017 through the California Cancer Registry (CCR) using the International Classification of Diseases (ICD) for Oncology, 3rd edition, code 27010 [13]. The CCR is a state-mandated population-based cancer surveillance system that collects incidence reports on more than 160,000 new cases of cancer diagnosed annually in California. The CCR is composed of three National Cancer Institute (NCI) Surveillance, Epidemiology, and End Results (SEER) registries that collect data on tumor characteristics, treatment, and patient demographic information. We linked the study cohort to the Office of Statewide Health Planning and Development (OSHPD) patient hospital and ED discharge records through a probabilistic linkage matching on social security number, date of birth, sex, and zip code. We included hospital inpatient discharge records in order to capture ED visits that resulted in a hospital admission.

Patients diagnosed at autopsy or death certificate only $(n=83)$ or missing date of last contact $(n=373)$ were excluded from analysis, resulting in a study population of 16,363. All analyses were overseen by the Institutional Review Board of the University of California, Davis.

\section{Emergency department information}

OSHPD contains information on each patient admission at nonfederal acute care hospitals in California. We selected the ED visits occurring in the 6 months before cervical cancer diagnosis. The discharge records include information on principal diagnosis, principal procedure, and up to 24 secondary diagnoses and procedures based on ICD, 9th Revision (ICD-9), ICD, 10th Revision (ICD-10), and Current Procedural Terminology (CPT) codes. Diagnoses and procedures suggestive of cervical cancer were determined from OSHPD ICD-9, ICD-10, and CPT codes. The list of diagnoses and procedures were identified from consultations with physicians and final review by a gynecologist, oncologist, and co-author (Tables 4 and 5). Women were classified as having a symptom or procedure suggestive of cervical cancer in the ED within 6 months prior to diagnosis (yes/no).

\section{Sociodemographic and clinical characteristics}

We obtained patient characteristics and treatment information from the CCR including stage and age at diagnosis, diagnosis year, health insurance type (for patients without an ED visit prior to diagnosis), race/ethnicity, neighborhood SES (nSES), rural/urban residence, comorbidity score, marital status, treatment at a NCI-designated cancer center, chemotherapy treatment, radiation treatment, and surgical treatment. From OSHPD we determined health insurance information for the patients seen in the ED prior to diagnosis.

Stage at diagnosis was assigned using the American Joint Committee on Cancer staging system rules. We categorized health insurance for patients without an ED visit from CCR information as private (HMO, PPO, fee for service, Veterans Affairs, Tricare, Medicare with supplement), public (Medicaid, Medicare with Medicaid eligibility, Medicare without supplement, county funded, Indian/public health service), uninsured, and unknown. For patients with an ED visit before diagnosis, we categorized health insurance from OSHPD information, as above, in order to best capture prediagnosis insurance status.

We classified race/ethnicity as non-Hispanic White $(\mathrm{NH}$ White), non-Hispanic Black (NH Black), Hispanic, Asian/ Pacific Islander (API), American Indian, and other/unknown, based on the North American Association of Central Cancer Registries' Hispanic and Asian/Pacific Islander Identification Algorithm (NHAPIIA) [14]. Neighborhood SES was assigned using an aggregate measure based on 2006-2010 American Community Survey data on education, occupation, unemployment, household income, poverty, rent, and home values of census tracts [15]. Rural/urban residence was based on Medical Service Study Area designations, a state-specific measure developed by the California Office of Statewide Health Planning and Development (OSHPD) to identify medically underserved areas [16].

We assessed patient comorbidities using the Charlson comorbidity index using categories of 0,1 , and 2 or more comorbidities based on sixteen medical conditions, 
excluding cancer diagnoses, reported in OSHPD discharge data linked to the CCR data [17]. Comorbidities could be evaluated for patients with an inpatient, emergency department, or ambulatory surgery center admission. Treatment at NCI-designated cancer centers was determined by reviewing all reporting facilities where patient treatment occurred.

\section{Statistical analysis}

We used descriptive statistics (frequencies, percentages) to assess unadjusted associations between sociodemographic and clinical characteristics by symptomatic ED visit prior to diagnosis. Multivariable logistic regression models were used to analyze sociodemographic and clinical factors associated with pre-diagnosis symptomatic ED visits. Results are presented as adjusted odds ratios (OR) and their associated $95 \%$ confidence intervals $(\mathrm{CI})$. We assessed collinearity between variables using eigenvalues and variance inflation factors. We used multivariable Cox proportional hazards regression to evaluate symptomatic presentation in the ED prior to diagnosis and overall (OS) and cancer-specific survival (CSS), adjusting for stage, age, diagnosis year, health insurance, race/ethnicity, nSES, rural/urban residence, comorbidity score, marital status, treatment at NCI-designated cancer center, and receipt of chemotherapy, radiation, and surgery. Survival time was calculated as days from the date of diagnosis to the date of death from any cause for OS and to the date of death from cancer for CSS or the date of last follow-up. We assessed proportional hazards assumptions with tests based on Schoenfeld residuals and inspection of the survival curves [survival function vs survival time and $\log (-\log )$ of the survival function versus the log of time] for all variables in the model. Variables that violated this assumption (chemotherapy, radiation) were included as stratifying variables. Results are presented as adjusted hazard ratios (HR) and their associated 95\% CIs. Analyses were conducted using SAS software version 9.4 (SAS Institute Inc., Cary, North Carolina).

\section{Results}

Of the 16,363 patients in the study cohort, 5,545 (33.9\%) had an ED visit in the 6 months before diagnosis. Of those who visited the ED, 4,590 (28.1\% of the study cohort) had a symptom or procedure suggestive of cervical cancer and $44.8 \%$ of these symptomatic women had more than one ED visit in the 6 months before their diagnosis. Compared to those without symptomatic ED visits, women with symptomatic visits had more late-stage disease (stages III/IV), were older ( $>50$ years), had public or no insurance, were NH Black, unmarried, and resided in the lowest SES neighborhoods (Table 1).
Multivariable logistic regression analysis demonstrated that increasing stage (vs. stage I) (stage II: OR 2.26; CI 1.98-2.58; stage III: OR 3.26; CI 2.94-3.62; stage IV: OR 5.29; CI 4.70-5.96), older age (vs. $<40$ years) $(40-50$ years: OR 1.21; CI 1.08-1.35; > 75 years: OR 1.38; CI 1.16-1.64), public insurance (OR 1.16; CI 1.06-1.27) and no insurance (OR 4.81; CI 4.06-5.71) (vs. private insurance), lower nSES (vs. highest nSES quintile) (lowest quintile: OR 1.76; CI 1.52-2.04; lower middle quintile: OR 1.47; CI 1.27-1.70; middle quintile: OR 1.21; CI 1.04-1.40), more comorbidities (vs Charlson score of 0) (Charlson score 1: OR 1.28; CI 1.15-1.42; Charlson score > 1: OR 2.58; CI 2.27-2.94), and being unmarried (vs. married) (OR 1.25; CI 1.15-1.36) were associated with increased odds of symptomatic presentation in the ED prior to diagnosis. Diagnosis in more recent years, 2011-2017 (vs. 2006-2010) was associated with decreased odds of symptomatic presentation in the ED (OR 0.88-0.89; CI 0.80-0.99) (Table 2).

Table 3 shows results of multivariable Cox proportional hazards analyses. Women presenting symptomatically in the ED in the 6 months prior to diagnosis (vs. those without symptomatic ED visits) had a $37 \%$ increased risk of death (HR 1.37; CI 1.28-1.47). Other factors associated with worse OS and CSS included increasing stage ( $p$-values $<0.001)$, older age groups $(>60$ years) ( $p$-values $\leq 0.008$ ), more comorbidity ( $p$-values $<0.001$ ), being unmarried ( $p$-values $\leq 0.015)$, and treatment at non-NCI -designated cancer centers ( $p$-values $<0.001)$. Being Hispanic or API (vs, NH White) was associated with a lower risk of death $(p$-values $<0.001)$.

\section{Discussion}

In our population-based study of over 16,000 women with cervical cancer, the $28 \%$ of women presenting symptomatically in the ED within 6 months prior to diagnosis were three-five times more likely to be diagnosed with stage III or IV disease and had worse overall and cervical cancerspecific survival. Women presenting symptomatically in the ED were nearly five times more likely to have no insurance and nearly two times more likely to reside in low-SES neighborhoods. This is consistent with prior studies showing poor primary care access and use of the ED for usual source of care among low-SES populations [7, 18]. Nearly half of women presenting symptomatically had more than one ED visit. Those diagnosed in more recent years were less likely to present symptomatically in the ED, which may relate to changes in healthcare policies in California to improve access to care. Overall, our study indicates that many women, especially low-SES women, are likely not benefiting from cervical cancer screening or care following an abnormal screen, have poor access to healthcare, and are 
Table 1 Characteristics of cervical cancer patients by emergency department (ED) visit status before diagnosis (0-6 months), 2006-2017, California, $n=16,363$

\begin{tabular}{|c|c|c|c|}
\hline \multirow[t]{2}{*}{ Characteristics } & $\begin{array}{l}\text { Had symptomatic }{ }^{\mathrm{a}} \text { ED visit } \\
\%(n)\end{array}$ & $\begin{array}{l}\text { No symptomatic ED } \\
\text { visit } \%(n)\end{array}$ & $\begin{array}{l}\text { Unknown ED } \\
\text { visit status \% (n) }\end{array}$ \\
\hline & $28.1 \%, n=4,590$ & $57.3 \%, n=9,377$ & $14.6 \%, n=2,396$ \\
\hline \multicolumn{4}{|l|}{ Stage } \\
\hline I & $25.2 \%(1156)$ & $54.7 \%(5129)$ & $47.3 \%(1134)$ \\
\hline II & $12.7 \%(581)$ & $11.5 \%(1077)$ & $10.9 \%(261)$ \\
\hline III & $28.6 \%(1312)$ & $17.3 \%(1620)$ & $17.9 \%(429)$ \\
\hline IV & $26.1 \%(1199)$ & $9.8 \%(918)$ & $11.7 \%(281)$ \\
\hline Unknown & $7.5 \%(342)$ & $6.8 \%(633)$ & $12.1 \%(291)$ \\
\hline \multicolumn{4}{|l|}{ Age group, years } \\
\hline$\leq 39$ & $21.4 \%(980)$ & $29.3 \%(2743)$ & $30.6 \%(732)$ \\
\hline $40-50$ & $27.7 \%(1271)$ & $27.8 \%(2607)$ & $32.2 \%(771)$ \\
\hline $51-60$ & $23.1 \%(1062)$ & $19.9 \%(1867)$ & $19.2 \%(461)$ \\
\hline $61-75$ & $18.7 \%(860)$ & $17.3 \%(1620)$ & $12.8 \%(307)$ \\
\hline$>75$ & $9.1 \%(417)$ & $5.8 \%(540)$ & $5.2 \%(125)$ \\
\hline \multicolumn{4}{|l|}{ Year of diagnosis } \\
\hline 2006-2010 & $43.8 \%(2010)$ & $43.6 \%(4084)$ & $34.4 \%(824)$ \\
\hline 2011-2013 & $24.7 \%(1132)$ & $24.6 \%(2311)$ & $23.1 \%(554)$ \\
\hline 2014-2017 & $31.5 \%(1448)$ & $31.8 \%(2982)$ & $42.5 \%(1018)$ \\
\hline \multicolumn{4}{|l|}{ Health insurance } \\
\hline Private & $48.1 \%(2207)$ & $61.1 \%(5725)$ & $25.6 \%(613)$ \\
\hline Public & $37.2 \%(1709)$ & $33.1 \%(3105)$ & $58.1 \%(1393)$ \\
\hline Uninsured & $13.5 \%(618)$ & $2.8 \%(263)$ & $7.3 \%(174)$ \\
\hline Unknown & $1.2 \%(56)$ & $3.0 \%(284)$ & $9.0 \%(216)$ \\
\hline \multicolumn{4}{|l|}{ Race/ethnicity } \\
\hline NH White & $39.9 \%(1833)$ & $43.9 \%(4120)$ & $14.7 \%(353)$ \\
\hline NH Black & $8.6 \%(394)$ & $5.6 \%(527)$ & $3.6 \%(86)$ \\
\hline Hispanic & $36.2 \%(1661)$ & $32.3 \%(3031)$ & $66.4 \%(1592)$ \\
\hline Asian/Pacific Islander & $13.8 \%(632)$ & $16.3 \%(1528)$ & $12.1 \%(291)$ \\
\hline American Indian & $1.2 \%(53)$ & $0.8 \%(78)$ & $0.3 \%(6)$ \\
\hline Other/Unknown & $0.4 \%(17)$ & $1.0 \%(93)$ & $2.8 \%(68)$ \\
\hline \multicolumn{4}{|c|}{ Neighborhood SES quintile } \\
\hline 1 Lowest & $30.8 \%(1415)$ & $20.8 \%(1952)$ & $36.9 \%(885)$ \\
\hline 2 & $24.3 \%(1114)$ & $21.6 \%(2025)$ & $25.8 \%(618)$ \\
\hline 3 & $19.3 \%(885)$ & $21.5 \%(2016)$ & $16.8 \%(403)$ \\
\hline 4 & $15.8 \%(723)$ & $19.7 \%(1851)$ & $12.0 \%(288)$ \\
\hline 5 Highest & $9.9 \%(453)$ & $16.3 \%(1533)$ & $8.4 \%(202)$ \\
\hline \multicolumn{4}{|l|}{ Rural/Urban location } \\
\hline Rural & $14.0 \%(641)$ & $13.1 \%(1227)$ & $8.4 \%(202)$ \\
\hline Urban & $86.0 \%(3949)$ & $86.9 \%(8150)$ & $91.6 \%(2194)$ \\
\hline \multicolumn{4}{|c|}{ Charlson comorbidity score } \\
\hline 0 & $61.7 \%(2833)$ & $67.3 \%(6308)$ & $0 \%(0)$ \\
\hline 1 & $19.0 \%(874)$ & $13.7 \%(1283)$ & $0 \%(0)$ \\
\hline$>1$ & $19.0 \%(873)$ & $5.7 \%(531)$ & $0 \%(0)$ \\
\hline Unknown & $0.2 \%(10)$ & $13.4 \%(1255)$ & $100.0 \%(2396)$ \\
\hline \multicolumn{4}{|l|}{ Marital status } \\
\hline Married & $36.6 \%(1679)$ & $46.9 \%(4396)$ & $36.1 \%(866)$ \\
\hline Not married & $60.4 \%(2771)$ & $48.3 \%(4531)$ & $52.0 \%(1247)$ \\
\hline Unknown & $3.1 \%(140)$ & $4.8 \%(450)$ & $11.8 \%(283)$ \\
\hline
\end{tabular}

NH non-Hispanic, SES socioeconomic status

${ }^{\mathrm{a}}$ For a full list of symptoms and procedures see Tables 4 and 5 
Table 2 Multivariable-adjusted ${ }^{\mathrm{a}}$ odds ratios (OR) and 95\% confidence intervals $(\mathrm{CI})$ of associations with emergency department (ED) care for symptoms of cervical cancer prior to diagnosis ${ }^{\mathrm{b}}$, 2006-2017, California

\begin{tabular}{|c|c|c|}
\hline \multirow[t]{2}{*}{ Characteristics } & \multicolumn{2}{|c|}{$\begin{array}{l}\text { ED visit with cervical cancer symp- } \\
\text { toms prior to diagnosis (vs no ED } \\
\text { visit) }\end{array}$} \\
\hline & OR (95\% CI) & $p$ value \\
\hline \multicolumn{3}{|l|}{ Stage } \\
\hline I & Reference & \\
\hline II & $2.26(1.98,2.58)$ & $<0.001$ \\
\hline III & $3.26(2.94,3.62)$ & $<0.001$ \\
\hline IV & $5.29(4.70,5.96)$ & $<0.001$ \\
\hline Unknown & $3.01(2.54,3.56)$ & $<0.001$ \\
\hline \multicolumn{3}{|l|}{ Age group, years } \\
\hline$\leq 39$ & Reference & \\
\hline $40-50$ & $1.21(1.08,1.35)$ & 0.001 \\
\hline $51-60$ & $1.06(0.93,1.19)$ & 0.382 \\
\hline $61-75$ & $0.98(0.86,1.12)$ & 0.760 \\
\hline$>75$ & $1.38(1.16,1.64)$ & $<0.001$ \\
\hline \multicolumn{3}{|l|}{ Year of diagnosis } \\
\hline 2006-2010 & Reference & \\
\hline 2011-2013 & $0.89(0.80,0.99)$ & 0.025 \\
\hline 2014-2017 & $0.88(0.80,0.96)$ & 0.006 \\
\hline \multicolumn{3}{|l|}{ Health insurance } \\
\hline Private & Reference & \\
\hline Public & $1.16(1.06,1.27)$ & 0.001 \\
\hline Uninsured & $4.81(4.06,5.71)$ & $<0.001$ \\
\hline Unknown & $0.56(0.40,0.77)$ & $<0.001$ \\
\hline \multicolumn{3}{|l|}{ Race/ethnicity } \\
\hline NH White & Reference & \\
\hline NH Black & $1.18(1.00,1.39)$ & 0.050 \\
\hline Hispanic & $1.1(0.99,1.21)$ & 0.063 \\
\hline Asian/Pacific Islander & $0.93(0.83,1.06)$ & 0.284 \\
\hline American Indian & $1.36(0.90,2.04)$ & 0.142 \\
\hline Other/Unknown & $0.92(0.51,1.65)$ & 0.787 \\
\hline \multicolumn{3}{|c|}{ Neighborhood SES quintile } \\
\hline 1 Lowest & $1.76(1.52,2.04)$ & $<0.001$ \\
\hline 2 & $1.47(1.27,1.70)$ & $<0.001$ \\
\hline 3 & $1.21(1.04,1.40)$ & 0.013 \\
\hline 4 & $1.16(1.00,1.35)$ & 0.051 \\
\hline 5 Highest & Reference & \\
\hline \multicolumn{3}{|l|}{ Rural/Urban location } \\
\hline Urban & Reference & \\
\hline Rural & $1.02(0.90,1.14)$ & 0.784 \\
\hline \multicolumn{3}{|c|}{ Charlson comorbidity score } \\
\hline 0 & Reference & \\
\hline 1 & $1.28(1.15,1.42)$ & $<0.001$ \\
\hline$>1$ & $2.58(2.27,2.94)$ & $<0.001$ \\
\hline Unknown & $0.01(0.01,0.02)$ & $<0.001$ \\
\hline \multicolumn{3}{|l|}{ Marital status } \\
\hline Married & Reference & \\
\hline Not married & $1.25(1.15,1.36)$ & $<0.001$ \\
\hline Unknown & $0.92(0.73,1.15)$ & 0.463 \\
\hline
\end{tabular}

Boldface indicates statistical significance $(p<0.05)$

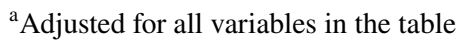

Table 2 (continued)

${ }^{\mathrm{b}}$ In the 6 months before diagnosis; For a full list of symptoms/procedures see Tables 4 and 5

NH non-Hispanic, SES socioeconomic status

diagnosed with advanced-stage disease outside of a primary care setting.

The $28 \%$ of our study cohort presenting symptomatically is on the high end of ranges previously described. Other U.S. studies, not focused on cervical cancer, have found the proportion of cancer patients beginning their diagnostic workup in the ED ranging from 5\% in 1992 to $32 \%$ in 2016 [11, 12, 19]. International studies on all cancers have reported diagnoses in the ED ranging from 14\% of cancer patients in 2013 to $20 \%$ in 2016 [20, 21]. Cancer presentation in the ED has been associated with less favorable patient characteristics such as advanced-stage disease and comorbid conditions, consistent with our findings [7, 12, 18].

Early cancer diagnosis improves survival [22]. Women diagnosed with cervical cancer as a result of screening are more likely to be asymptomatic and have early-stage disease [8]. Screening rates vary by socioeconomic status with lower screening rates among poor and less educated women [5, 23]. Screening utilization is approximately $20 \%$ lower in women with less than a high school education compared to college graduates, $15 \%$ lower in women earning less than $139 \%$ of federal poverty level compared to those earning greater than $400 \%$, and $20 \%$ lower in women without a usual source of healthcare [5]. This may explain our findings of increased odds of symptomatic presentation in the ED among women residing in low-SES neighborhoods and among those with public or no insurance. In addition, unmarried women were more likely to present symptomatically, consistent with findings showing delayed cervical cancer diagnosis among unmarried women [24]. By age group, women $>75$ had the greatest likelihood of symptomatic presentation in the ED. High cervical cancer incidence and mortality in older women has been noted, but current guidelines do not recommend cervical cancer screening in those over age 65 who have had adequate negative prior screening within the past 10 years, and no history of CIN2+ (cervical intraepithelial neoplasia grade 2 or more) within the past 25 years [25-27]. Our study was unable to determine whether women in this age category met the criteria to exit screening.

We found that women diagnosed in more recent years had a decreased likelihood of symptomatic presentation in the ED. From 2010 to 2014, several policies were enacted in California that may have improved access to preventive health care in our study cohort. Starting in late 2010, the Affordable Care Act (ACA) Dependent Care Expansion permitted young adults to remain on their parents' health 
Table 3 Multivariableadjusted ${ }^{\mathrm{a}}$ hazard ratios (HR) and $95 \%$ confidence intervals (CI) for associations between emergency department (ED) care for symptoms of cervical cancer prior to diagnosis ${ }^{\mathrm{b}}$ and mortality, 2006-2017, California

\begin{tabular}{|c|c|c|c|c|}
\hline \multirow[t]{2}{*}{ Characteristics } & \multicolumn{2}{|l|}{ Overall mortality } & \multicolumn{2}{|c|}{ Cancer-specific mortality } \\
\hline & $\mathrm{HR}(95 \% \mathrm{CI})$ & $p$ value & HR (95\% CI) & $p$ value \\
\hline \multicolumn{5}{|l|}{ Symptoms at the ED } \\
\hline No & Reference & & & \\
\hline Yes & $1.37(1.28,1.46)$ & $<0.001$ & $1.37(1.28,1.47)$ & $<0.001$ \\
\hline Unknown & $0.86(0.74,0.99)$ & 0.034 & $0.78(0.67,0.92)$ & 0.003 \\
\hline \multicolumn{5}{|l|}{ Stage } \\
\hline I & Reference & & & \\
\hline II & $1.98(1.76,2.24)$ & $<0.001$ & $2.49(2.15,2.87)$ & $<0.001$ \\
\hline III & $3.51(3.16,3.90)$ & $<0.001$ & $4.73(4.17,5.35)$ & $<0.001$ \\
\hline IV & $8.13(7.32,9.03)$ & $<0.001$ & $11.71(10.34,13.26)$ & $<0.001$ \\
\hline Unknown & $3.04(2.69,3.44)$ & $<0.001$ & $4.10(3.55,4.73)$ & $<0.001$ \\
\hline \multicolumn{5}{|l|}{ Age group, years } \\
\hline$\leq 39$ & Reference & & & \\
\hline $40-50$ & $1.12(1.02,1.22)$ & 0.015 & $1.05(0.95,1.15)$ & 0.342 \\
\hline $51-60$ & $1.23(1.12,1.34)$ & $<0.001$ & $1.06(0.96,1.16)$ & 0.281 \\
\hline $61-75$ & $1.51(1.38,1.66)$ & $<0.001$ & $1.15(1.04,1.27)$ & 0.008 \\
\hline$>75$ & $2.64(2.36,2.94)$ & $<0.001$ & $1.87(1.65,2.12)$ & $<0.001$ \\
\hline \multicolumn{5}{|l|}{ Year of diagnosis } \\
\hline 2006-2010 & Reference & & & \\
\hline 2011-2013 & $1.05(0.98,1.12)$ & 0.156 & $1.05(0.97,1.13)$ & 0.212 \\
\hline 2014-2017 & $0.95(0.89,1.02)$ & 0.165 & $0.94(0.87,1.01)$ & 0.086 \\
\hline \multicolumn{5}{|l|}{ Health insurance } \\
\hline Private & Reference & & & \\
\hline Public & $1.03(0.97,1.10)$ & 0.287 & $0.98(0.92,1.05)$ & 0.606 \\
\hline Uninsured & $0.99(0.89,1.10)$ & 0.888 & $0.96(0.86,1.08)$ & 0.538 \\
\hline Unknown & $1.19(1.01,1.41)$ & 0.041 & $1.15(0.95,1.39)$ & 0.147 \\
\hline \multicolumn{5}{|l|}{ Race/ethnicity } \\
\hline NH White & Reference & & & \\
\hline NH Black & $1.08(0.97,1.20)$ & 0.145 & $1.07(0.95,1.20)$ & 0.250 \\
\hline Hispanic & $0.85(0.79,0.91)$ & $<0.001$ & $0.86(0.80,0.93)$ & $<0.001$ \\
\hline Asian/Pacific Islander & $0.81(0.75,0.88)$ & $<0.001$ & $0.84(0.77,0.93)$ & $<0.001$ \\
\hline American Indian & $0.86(0.63,1.16)$ & 0.311 & $0.85(0.61,1.19)$ & 0.347 \\
\hline Other/Unknown & $0.13(0.06,0.29)$ & $<0.001$ & $0.06(0.01,0.23)$ & $<0.001$ \\
\hline \multicolumn{5}{|c|}{ Neighborhood SES quintile } \\
\hline 1 Lowest & $1.13(1.02,1.25)$ & 0.018 & $1.09(0.98,1.22)$ & 0.120 \\
\hline 2 & $1.08(0.97,1.19)$ & 0.153 & $1.02(0.91,1.15)$ & 0.683 \\
\hline 3 & $1.04(0.93,1.15)$ & 0.509 & $1.02(0.91,1.14)$ & 0.723 \\
\hline 4 & $0.95(0.86,1.06)$ & 0.397 & $0.95(0.85,1.07)$ & 0.430 \\
\hline 5 Highest & Reference & & & \\
\hline \multicolumn{5}{|l|}{ Rural/Urban location } \\
\hline Rural & $1.02(0.94,1.11)$ & 0.660 & $1.01(0.92,1.11)$ & 0.839 \\
\hline Urban & Reference & & & \\
\hline \multicolumn{5}{|c|}{ Charlson comorbidity score } \\
\hline 0 & Reference & & & \\
\hline 1 & $1.30(1.21,1.41)$ & $<0.001$ & $1.21(1.11,1.32)$ & $<0.001$ \\
\hline$>1$ & $1.91(1.77,2.07)$ & $<0.001$ & $1.67(1.53,1.83)$ & $<0.001$ \\
\hline Unknown & $1.14(1.02,1.28)$ & 0.022 & $1.11(0.98,1.25)$ & 0.110 \\
\hline \multicolumn{5}{|l|}{ Marital status } \\
\hline Married & Reference & & & \\
\hline Not married & $1.08(1.02,1.15)$ & 0.008 & $1.09(1.02,1.16)$ & 0.015 \\
\hline
\end{tabular}


Table 3 (continued)

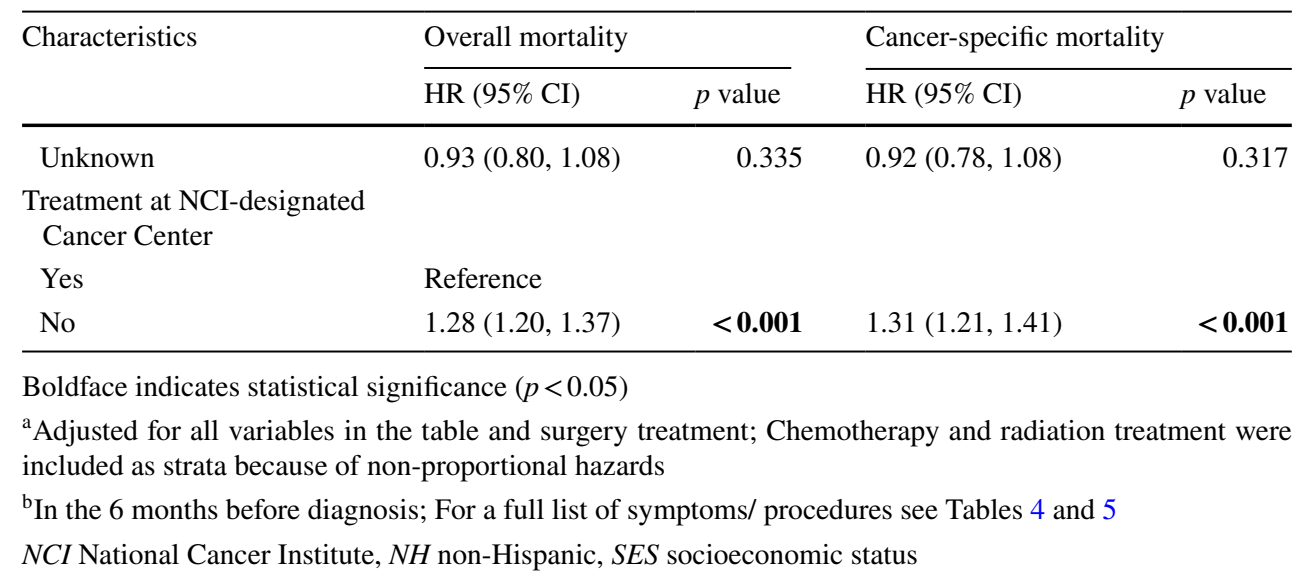

insurance until age 26 [28]. From 2011 to 2013, the LowIncome Health Plan extended Medicaid coverage to uninsured adults ages 19-64 with a family income up to $200 \%$ of the Federal Poverty Level [29]. In January 2014, the full ACA was implemented, expanding Medicaid coverage and providing a private health insurance marketplace with subsidies for eligible individuals [30]. Expanded healthcare provisions may have resulted in more primary care screening with follow-up and less reliance on the ED during the later years of our study period.

We did not observe differences by race/ethnicity for symptomatic presentation in the ED, unlike previous studies such as Livingwood et al. that found higher proportions of Black patients beginning their cancer diagnoses in the ED [12]. However, we did find better survival among Hispanic and API women compared to NH White women. Our survival findings are consistent with prior studies including those from Nghiem et al. that found that Asian American women with cervical cancer (vs. NH White women) had higher survival rates, and Patel et al. that found that Hispanic women had a survival advantage compared to non-Hispanic White women with cervical cancer [31, 32]. Factors found to be associated with better survival in Asian and/or Hispanic women include higher SES, having family support (spouses, domestic partners), and better adherence to recommended treatment [24, 32, 33]. The effect of nativity could also play a role. Studies have revealed that foreign-born Hispanic women have better survival than their U.S. born counterparts (Hispanic paradox) [34, 35]. It has been speculated that Asian American women may be subject to a similar effect [32]. Further study is needed to better understand these associations.

Women in our study presenting symptomatically in the ED had a $37 \%$ increased risk of death after controlling for factors known to be associated with survival, including stage at diagnosis, age, comorbidity, and treatment at NCI-designated cancer centers [22, 36, 37]. This is in agreement with other studies that have found later stage disease and worse survival among cancer patients beginning their diagnostic workup in the ED [12]. However, prior studies have not evaluated cervical cancer.

Our study had some limitations. We lacked information on cervical cancer screening and HPV vaccination uptake among our cohort. Although it is likely that a large percentage of our cohort presenting symptomatically with advanced-stage disease had not been screened, we were unable to confirm this. Additionally, we were unable to identify patients presenting symptomatically in outpatient settings. Finally, $14.6 \%$ of our study cohort had unknown ED visit status. These patients had missing social security numbers and could not be linked to ED records. It is therefore possible that we underestimated the number of women with symptomatic ED visits prior to diagnosis. Although the women with unknown ED visit status had some similarities to those with symptomatic visits such as more public and no insurance and high percentages residing in low-SES neighborhoods, they had similar proportions of late-stage disease to those without symptomatic ED visits and they had better OS and CSS. In sensitivity analyses combining the unknowns with those without ED visits, OS and CSS remained unchanged. Despite these limitations, our study was able to estimate the proportion of women with cervical cancer who presented symptomatically prior to their diagnosis and to describe their characteristics and outcomes in a large ethnically and geographically diverse state.

Nearly one-third of cervical cancer patients in California present symptomatically over 50 years after the introduction of Pap tests and over 15 years after the creation of the National Breast and Cervical Cancer Early Detection Program [38]. Additionally, some patients in our cohort were eligible for HPV vaccination. Early diagnosis through screening, before symptoms appear, can significantly 
Table 4 Diagnoses ${ }^{\mathrm{a}}$ suggestive of cervical cancer recorded in the emergency department (ED) or subsequent hospital stay in the 6 months prior to diagnosis with cervical cancer among the 5,545 patients with an ED visit

\begin{tabular}{|c|c|}
\hline Diagnoses & $\%(n)$ \\
\hline $\begin{array}{l}\text { Disorders of the genital tract } \\
\text { Dysplasia of cervix, erosion of cervix } \\
\text { Polyp of cervix } \\
\text { Inflammatory disease of cervix, vagina, or vulva } \\
\text { Noninflammatory disorders of cervix, vagina, vulva, or perineum } \\
\text { Leukorrhea, noninfective } \\
\text { Dyspareunia, post coital bleeding } \\
\text { Excessive or frequent menstruation, dysmenorrhea } \\
\text { Metrorrhagia, postmenopausal bleeding } \\
\text { Genital fistula } \\
\text { Hypertrophy of uterus }\end{array}$ & $49.1 \%(2724)$ \\
\hline $\begin{array}{l}\text { Disorders of the urinary tract } \\
\text { Hydronephrosis } \\
\text { Hydroureter, ureter obstruction } \\
\text { Urinary obstruction } \\
\text { Bladder obstruction } \\
\text { Retention of urine } \\
\text { Urinary hesitancy, frequency, dysuria } \\
\text { Oliguria and anuria } \\
\text { Hematuria } \\
\text { Renal colic } \\
\text { Kidney failure }\end{array}$ & $18.5 \%(1026)$ \\
\hline $\begin{array}{l}\text { Genitourinary neoplasm } \\
\text { Carcinoma in situ cervix } \\
\text { Malignant neoplasm of cervix } \\
\text { Malignant neoplasm, pelvis } \\
\text { Malignant neoplasm of endocervix, exocervix } \\
\text { Malignant or benign neoplasm vagina, lower uterine segment, female genitalia } \\
\text { Malignant or benign neoplasm bladder, ureter, urethra }\end{array}$ & $42.7 \%(2367)$ \\
\hline $\begin{array}{l}\text { Pain or mass } \\
\text { Abdominal pain } \\
\text { Abdominal mass } \\
\text { Pelvic pain } \\
\text { Pelvic mass } \\
\text { Low back pain } \\
\text { Neoplasm-related pain } \\
\text { Ascites }\end{array}$ & $21.0 \%$ \\
\hline $\begin{array}{l}\text { Blood loss/anemia } \\
\text { Acute post-hemorrhagic anemia } \\
\text { Iron deficiency anemia secondary to blood loss } \\
\text { Anemia in neoplastic disease } \\
\text { Anemia of other chronic disease } \\
\text { Other iron deficiency anemias }\end{array}$ & $36.1 \%(2001)$ \\
\hline
\end{tabular}

${ }^{\mathrm{a} B a s e d}$ on ICD9 and ICD10 diagnosis codes decrease morbidity and mortality in this highly preventable disease [1]. Symptomatic ED use, more likely in women residing in low-SES neighborhoods or with public or no insurance, suggests poor access to preventive healthcare. Almost half of the women presenting symptomatically in our study had more than one ED visit prior to their diagnosis. ED use patterns can reflect the healthcare delivery of a community and be a marker of deficiencies in the primary care infrastructure [11]. Our findings suggest that efforts should be made to increase adherence to cervical cancer screening 
Table 5 Procedures ${ }^{\mathrm{a}}$ suggestive of cervical cancer recorded in the emergency department or subsequent hospital stay in the 6 months prior to diagnosis with cervical cancer among the 5,545 patients with an ED visit

\begin{tabular}{lc}
\hline Procedures & $\%(n)$ \\
\hline Operations on the genital tract & $34.3 \%(1904)$ \\
Operations on cervix (excision, resection, drainage) & \\
Excision and incision of uterus including hysterectomy & \\
Diagnostic procedures (biopsy, excision) on vulva, vagina, and cul-de-sac & \\
Hemostatic agent for nonobstetrical vaginal hemorrhage & $14.3 \%$ (794) \\
Endometrial sampling, extraction & \\
Operations on urinary system & \\
Nephrostomy, replacement of nephrostomy tube & $6.8 \%$ (376) \\
Operations (excision, drainage, dilation,) on ureter (including stent placement), urinary bladder, urethra, \\
kidney & $39.2 \%$ (2171) \\
Ureteral or bladder catheterization & \\
Diagnostic procedures (cystourethroscopy, ureteroscopy, pyeloscopy) of kidney, bladder, & \\
ureter, urethra & \\
Operations on lymph nodes & \\
Biopsy, excision, or dissection of lymph node (inguinal, pelvis) & \\
Diagnostic and therapeutic procedures & \\
Gynecological examination: pelvic exam & \\
Diagnostic proctoscopy, sigmoidoscopy, colonoscopy & \\
Transfusion of blood & \\
Injection or infusion of cancer chemotherapeutic substance & \\
Imaging urinary system (X-ray, ultrasound, other) & \\
\hline
\end{tabular}

${ }^{\mathrm{a} B}$ ased on ICD9, ICD10, and CPT4 procedure codes guidelines, increase uptake of HPV vaccination, and ensure proper follow-up care especially among low-SES women. Further studies investigating the barriers to care low-SES women face and strategies to expand preventive care are warranted.

Author contributions Study concept and design: FBM, CRM, VAK. Acquisition, analysis, or interpretation of data: FBM, JJPC, CRM, AP-P, VAK, THMK. Drafting of the manuscript: FBM. Critical revision of the manuscript for important intellectual content: All authors. Study supervision: CRM, AP-P, THMK.

Funding This work was supported by the California Department of Public Health as part of the statewide cancer reporting program mandated by California Health and Safety Code Section 103885; the National Cancer Institute's Surveillance, Epidemiology and End Results Program under contracts awarded to the Cancer Prevention Institute of California, the University of Southern California, and the Public Health Institute; and the Centers for Disease Control and Prevention's National Program of Cancer Registries, under agreement awarded to the California Department of Public Health. The ideas and opinions expressed herein are those of the author(s) and endorsement by the State of California, Department of Public Health, the National Cancer Institute, the Centers for Disease Control and Prevention, or their Contractors and Subcontractors is not intended nor should be inferred.
Data availability Per contract with the State of California, the data used in this study cannot be shared. However, investigators can apply directly to the California Cancer Registry to request these data (https:// www.ccrcal.org/retrieve-data/).

Code availability Programming codes used for the analysis can be requested from the corresponding author.

\section{Declarations}

Conflict of interest There are no conflict of interest to report.

Open Access This article is licensed under a Creative Commons Attribution 4.0 International License, which permits use, sharing, adaptation, distribution and reproduction in any medium or format, as long as you give appropriate credit to the original author(s) and the source, provide a link to the Creative Commons licence, and indicate if changes were made. The images or other third party material in this article are included in the article's Creative Commons licence, unless indicated otherwise in a credit line to the material. If material is not included in the article's Creative Commons licence and your intended use is not permitted by statutory regulation or exceeds the permitted use, you will need to obtain permission directly from the copyright holder. To view a copy of this licence, visit http://creativecommons.org/licenses/by/4.0/. 


\section{References}

1. Yang DX, Soulos PR, Davis B, Gross CP, Yu JB (2018) Impact of widespread cervical cancer screening: number of cancers prevented and changes in race-specific incidence. Am J Clin Oncol 41(3):289-294. https://doi.org/10.1097/coc.0000000000000264

2. Walboomers JM, Jacobs MV, Manos MM, Bosch FX, Kummer JA, Shah KV et al (1999) Human papillomavirus is a necessary cause of invasive cervical cancer worldwide. J Pathol 189(1):1219. https://doi.org/10.1002/(sici)1096-9896(199909)189:1\%3c12:: Aid-path431\%3e3.0.Co;2-f

3. Howlader N, Noone AM, Krapcho M, Miller D, Brest A, Yu M et al (2020) SEER cancer statistics review, 1975-2017. National Cancer Institute, Bethesda, MD

4. Siegel RL, Miller KD, Jemal A (2020) Cancer statistics, 2020. CA Cancer J Clin 70(1):7-30. https://doi.org/10.3322/caac.21590

5. White A, Thompson TD, White MC, Sabatino SA, de Moor J, Doria-Rose PV et al (2017) Cancer screening test use-United States, 2015. Morb Mortal Wkly Rep 66(8):201-206. https://doi. org/10.15585/mmwr.mm6608a1

6. Chen ST, Huybrechts KF, Bateman BT, Hernández-Díaz S (2020) Trends in human papillomavirus vaccination in commercially insured children in the United States. Pediatrics. https://doi.org/ 10.1542/peds.2019-3557

7. Pruitt SL, Werner CL, Borton EK, Sanders JM, Balasubramanian BA, Barnes A et al (2018) Cervical cancer burden and opportunities for prevention in a safety-net healthcare system. Cancer Epidemiol Biomark Prev 27(12):1398-1406. https://doi.org/10. 1158/1055-9965.Epi-17-0912

8. Myriokefalitaki E, Potdar N, Barnfield L, Davies Q, Moss EL (2016) Cervical cancer still presents symptomatically 20 years after the introduction of a structured national screening programme. Cytopathology 27(4):229-236. https://doi.org/10.1111/ cyt. 12315

9. Albright BB, Delgado MK, Latif NA, Giuntoli RL 2nd, Ko EM, Haggerty AF (2019) Treat-and-release emergency department utilization by patients with gynecologic cancers. J Oncol Pract 15(5):e428-e438. https://doi.org/10.1200/jop.18.00639

10. Albright BB, Delgado MK, Latif NA, Giuntoli RL, Ko EM, Haggerty AF (2020) Emergency department utilization by patients with gynecologic cancer in the United States. Int J Gynecol Cancer. https://doi.org/10.1136/ijgc-2020-001520

11. Hargarten SW, Richards MJ, Anderson AJ (1992) Cancer presentation in the emergency department: a failure of primary care. Am J Emerg Med 10(4):290-293. https://doi.org/10.1016/07356757(92)90004-h

12. Livingood WC, Smotherman C, Lukens-Bull K, Aldridge P, Kraemer DF, Wood DL et al (2016) An elephant in the emergency department: symptom of disparities in cancer care. Popul Health Manag 19(2):95-101. https://doi.org/10.1089/pop.2015.0118

13. NCI Surveillance Epidemiology and End Results Program. Site Recode ICD-O-3/WHO 2008 Definition 2008 [cited 2020 March 12]. Available from https://seer.cancer.gov/siterecode/icdo3 dwhoheme/

14. North American Association of Central Cancer Registries. NAACCR Hispanic and Asian/Pacific Islander Identification Algorithm (NHAPIIA) 2017 [cited 2020 July 15]. Available from https://www.naaccr.org/analysis-and-data-improvement-tools/\# NHAPIIA

15. Yang JSC, Harrati A, Clarke C, Keegan THM, Gomez SL (2014) Developing an area-based socioeconomic measure from American Community Survey data. Cancer Prevention Institute of California, Fremont, CA
16. Office of Statewide Health Planning and Development. Medical Service Study Area (MSSA) — census detail, 2013: California Health and Human Services Open Data Portal; 2013 [September 8, 2020]

17. Lichtensztajn DY, Giddings BM, Morris CR, Parikh-Patel A, Kizer KW (2017) Comorbidity index in central cancer registries: the value of hospital discharge data. Clin Epidemiol 9:601-609. https://doi.org/10.2147/clep.s146395

18. Ramondetta LM, Meyer LA, Schmeler KM, Daheri ME, Gallegos J, Scheurer M et al (2015) Avoidable tragedies: disparities in healthcare access among medically underserved women diagnosed with cervical cancer. Gynecol Oncol 139(3):500-505. https://doi.org/10.1016/j.ygyno.2015.10.017

19. Polednak AP (2000) Inpatient hospital admission through an emergency department in relation to stage at diagnosis of colorectal cancer. Cancer Detect Prev 24(3):283-289

20. Tsang C, Bottle A, Majeed A, Aylin P (2013) Cancer diagnosed by emergency admission in England: an observational study using the general practice research database. BMC Health Serv Res 13:308. https://doi.org/10.1186/1472-6963-13-308

21. Rogers MJ, Matheson LM, Garrard B, Mukaro V, Riches S, Sheridan M et al (2016) Cancer diagnosed in the Emergency Department of a Regional Health Service. Aust J Rural Health 24(6):409-414. https://doi.org/10.1111/ajr.12280

22. Howlader N NA, Krapcho M, Miller D, Bishop K, et al. SEER cancer statistics review, 1975-20172020 October 4, 2020. Available from https://seer.cancer.gov/csr/1975_2017/ based on November 2019 SEER data submission

23. Goding Sauer A, Siegel RL, Jemal A, Fedewa SA (2019) Current prevalence of major cancer risk factors and screening test use in the United States: disparities by education and race/ethnicity. Cancer Epidemiol Biomark Prev 28(4):629-642. https://doi.org/ 10.1158/1055-9965.Epi-18-1169

24. Saghari S, Ghamsary M, Marie-Mitchell A, Oda K, Morgan JW (2015) Sociodemographic predictors of delayed-versus early-stage cervical cancer in California. Ann Epidemiol 25(4):250-255. https://doi.org/10.1016/j.annepidem.2015.01.008

25. Curry SJ, Krist AH, Owens DK, Barry MJ, Caughey AB, Davidson KW et al (2018) Screening for cervical cancer: US preventive services task force recommendation statement. J Am Med Assoc 320(7):674-686. https://doi.org/10.1001/jama.2018.10897

26. Hammer A, Fuglsang K, Høgsbjerg K, Blaakær J (2015) Screening for cervical cancer in women older than 65 years will probably reduce the incidence and mortality. Ugeskr Laeger 177(23):V12140697

27. Fontham ETH, Wolf AMD, Church TR, Etzioni R, Flowers CR, Herzig A et al (2020) Cervical cancer screening for individuals at average risk: 2020 guideline update from the American Cancer Society. CA Cancer J Clin 70(5):321-46. https://doi.org/10.3322/ caac. 21628

28. Breslau J, Stein BD, Han B, Shelton S, Yu H (2018) Impact of the affordable care act's dependent coverage expansion on the health care and health status of young adults: what do we know so far? Med Care Res Rev 75(2):131-152. https://doi.org/10.1177/10775 58716682171

29. Golberstein E, Gonzales G, Sommers BD (2015) California's early ACA expansion increased coverage and reduced out-of-pocket spending for the state's low-income population. Health Affairs (Project Hope) 34(10):1688-1694. https://doi.org/10.1377/hltha ff. 2015.0290

30. Moss HA, Havrilesky LJ, Chino J (2017) Insurance coverage among women diagnosed with a gynecologic malignancy before and after implementation of the Affordable Care Act. Gynecol Oncol 146(3):457-464. https://doi.org/10.1016/j.ygyno.2017.06. 012 
31. Patel DA, Barnholtz-Sloan JS, Patel MK, Malone JM Jr, Chuba PJ, Schwartz K (2005) A population-based study of racial and ethnic differences in survival among women with invasive cervical cancer: analysis of Surveillance, Epidemiology, and End Results data. Gynecol Oncol 97(2):550-558. https://doi.org/10.1016/j.ygyno. 2005.01.045

32. Nghiem VT, Davies KR, Chan W, Mulla ZD, Cantor SB (2016) Disparities in cervical cancer survival among Asian-American women. Ann Epidemiol 26(1):28-35. https://doi.org/10.1016/j. annepidem.2015.10.004

33. Cantwell CJ, Moroney MR, Sheeder J, Guntupalli SR (2021) Assessing inequities in cervical cancer quality of care and survival related to ethnicity and socioeconomic factors. J Low Genit Tract Dis 25(3):205-209. https://doi.org/10.1097/lgt.0000000000 000611

34. Montealegre JR, Zhou R, Amirian ES, Follen M, Scheurer ME (2013) Nativity disparities in late-stage diagnosis and cause-specific survival among Hispanic women with invasive cervical cancer: an analysis of Surveillance, Epidemiology, and End Results data. Cancer Causes Control 24(11):1985-1994. https://doi.org/ 10.1007/s 10552-013-0274-1

35. Gomez N, Guendelman S, Harley KG, Gomez SL (2015) Nativity and neighborhood characteristics and cervical cancer stage at diagnosis and survival outcomes among Hispanic women in California. Am J Public Health 105(3):538-545. https://doi.org/ 10.2105/ajph.2014.302261

36. Ho G, Wun T, Muffly L, Li Q, Brunson A, Rosenberg AS et al (2018) Decreased early mortality associated with the treatment of acute myeloid leukemia at National Cancer Institute-designated cancer centers in California. Cancer. https://doi.org/10.1002/cncr. 31296

37. Sarfati D, Koczwara B, Jackson C (2016) The impact of comorbidity on cancer and its treatment. CA Cancer J Clin 66(4):337-50. https://doi.org/10.3322/caac.21342

38. Centers for Disease Control and Prevention (2021) National Breast and Cervical Cancer Early Detection Program: Division of Cancer Prevention and Control. [cited 2021 July 23]. Available from https://www.cdc.gov/cancer/nbccedp/about.htm

Publisher's Note Springer Nature remains neutral with regard to jurisdictional claims in published maps and institutional affiliations. 